University of Wollongong

Research Online

Faculty of Engineering and Information

Faculty of Engineering and Information

Sciences - Papers: Part A

Sciences

$1-1-2012$

\title{
Simulation model of a grid-connected single-phase photovoltaic system in PSCAD/EMTDC
}

\author{
Brian K. Perera \\ University of Wollongong, bkp389@uowmail.edu.au \\ Sridhar R. Pulikanti \\ University of Wollongong, sridhar@uow.edu.au \\ Philip Ciufo \\ University of Wollongong, ciufo@uow.edu.au \\ Sarath Perera \\ University of Wollongong, sarath@uow.edu.au
}

Follow this and additional works at: https://ro.uow.edu.au/eispapers

Part of the Engineering Commons, and the Science and Technology Studies Commons

Research Online is the open access institutional repository for the University of Wollongong. For further information contact the UOW Library: research-pubs@uow.edu.au 


\title{
Simulation model of a grid-connected single-phase photovoltaic system in PSCAD/EMTDC
}

\author{
Abstract \\ In this paper, a complete simulation model of a grid-connected single-phase two-stage photovoltaic (PV) \\ system with associated controllers is presented. The simulation model is developed in PSCAD/EMTDC \\ simulation program. The component models of the grid-connected PV system include a PV array, a dc-dc \\ boost converter, a voltage source converter (VSC) and an LCL filter. Components of the LCL filter, the dc- \\ link capacitor of the VSC and the inductor of the dc-dc boost converter are established theoretically and \\ that are used in modelling the grid-connected PV system. The control architecture of the presented \\ system incorporates a synchronous reference frame phase-locked-loop (s-PLL), a stationary frame \\ current controller, a dc-link voltage controller, a dc-dc boost converter controller and a maximum power \\ point tracking (MPPT) algorithm. Control design methodologies are described in detail. Simulation \\ studies confirm that the modelling and control design approaches taken are robust and lead to a system \\ with acceptable performance.

\section{Keywords} \\ grid, simulation, pscad, model, connected, emtdc, single, phase, photovoltaic, system \\ Disciplines \\ Engineering | Science and Technology Studies

\section{Publication Details} \\ B. K. Perera, S. R. Pulikanti, P. Ciufo \& S. Perera, "Simulation model of a grid-connected single-phase \\ photovoltaic system in PSCAD/EMTDC," in POWERCON: IEEE International Conference on Power Systems \\ Technology, 2012, pp. 1-6.
}




\title{
Simulation Model of a Grid-Connected Single-Phase Photovoltaic System in PSCAD/EMTDC
}

\author{
Brian K. Perera, Student Member, IEEE, Sridhar R. Pulikanti, Member, IEEE, Philip Ciufo, Senior Member, IEEE \\ and Sarath Perera, Member, IEEE
}

\begin{abstract}
In this paper, a complete simulation model of a gridconnected single-phase two-stage photovoltaic (PV) system with associated controllers is presented. The simulation model is developed in PSCAD/EMTDC simulation program. The component models of the grid-connected PV system include a PV array, a dc-dc boost converter, a voltage source converter (VSC) and an LCL filter. Components of the LCL filter, the dc-link capacitor of the VSC and the inductor of the dc-dc boost converter are established theoretically and that are used in modelling the grid-connected PV system. The control architecture of the presented system incorporates a synchronous reference frame phase-locked-loop (s-PLL), a stationary frame current controller, a dc-link voltage controller, a dc-dc boost converter controller and a maximum power point tracking (MPPT) algorithm. Control design methodologies are described in detail. Simulation studies confirm that the modelling and control design approaches taken are robust and lead to a system with acceptable performance.
\end{abstract}

Index Terms-Control, modelling, photovoltaic systems, voltage source converter.

\section{INTRODUCTION}

$\mathbf{T}$ HE modern, power distribution grid is undergoing a significant change with the connection of a large number of small capacity distributed generation (DG) units such as photovoltaic (PV) systems, energy storage systems, and in some cases, wind turbines. Small scale PV systems $(0-10 \mathrm{~kW})$ are the type of renewable energy DG units that are mostly connected to the power distribution grid. The majority of small scale PV systems are domestic roof-top type installations and are generally single-phase systems. Rebates and concession schemes that were introduced by the government for installing small scale PV systems along with price reductions in PV panels and power electronic converter systems, are the main reasons for the increased number of grid-connected small scale PV systems in the power distribution grid.

Operational or power quality problems may be occurred in the power distribution grid with integration of small scale multiple PV systems. The integration of small scale multiple PV systems means that the power distribution grid may increase the susceptibility to voltage fluctuations due to injected

This work was supported by the Australian Research Council (ARC) and Essential Energy Linkage Grant LP100100618.

B. K. Perera, S. R. Pulikanti, P. Ciufo and S. Perera are members of the Endeavour Energy Power Quality and Reliability Centre, School of Electrical, Computer and Telecommunications Engineering, University of Wollongong, NSW 2522, Australia (email:ciufo@uow.edu.au).

NOTICE: this is the authors' version of a work that was accepted for publications. Changes resulting from the publishing process, such as peer review, editing, corrections, structural formatting, and other quality control mechanisms may not be reflected in this document. Changes may have been made to this work since it was submitted for publication. A definitive version was subsequently published in the Proceedings of the IEEE International Conference on Power Systems Technology (POWERCON), Oct. 2012, DOI:10.1109/PowerCon.2012.6401379 active power variations from the PV systems, depending on conditions such as the time of day and weather. Such variations in output power can cause voltage fluctuations (either slow or fast) in the power distribution grid where concentrated PV installations exist [1]. Since PV systems are interfaced to the power distribution grid through power electronic converters that is equivalent to a condition where there is no mechanical inertia, the speed of response of PV systems in relation to reduction or increase in available power can be very fast indeed [2]. When multiple inverter interfaced PV systems are integrated into the power distribution grid, there may be operational and control interactions between these systems or with the grid [3]-[6]. These interactions may cause unintentional tripping of PV systems, possibly making the grid unstable or a system may fail to disconnect when it is necessary to do so, creating a hazardous situation. Therefore, possible mechanisms and causes for operational and control interactions should be identified first, to propose any mitigation techniques to avoid undesirable interactions among multiple PV systems for a stable operation of the power distribution grid. Furthermore, there can be potential instabilities within a grid-connected PV system if the operating point of the PV array is moved towards the constant current region of the characteristic curve of a PV array [7]. The prior identification of possibilities of occurring mentioned problems in a power distribution grid with multiple PV systems is critical for both power utilities and PV system designers.

In order to investigate possible rapid and slow voltage fluctuations at the grid interface, operational and control interactions in the presence of multiple grid-connected PV systems and also to evaluate potential instabilities within a gridconnected PV system, a detailed model of a grid-connected single-phase PV system is necessary. The knowledge on component level modelling of a grid-connected PV system is available with recently published literature for both 3-phase and single-phase systems [8], [9]. But a complete model of a grid-connected single-phase PV system with associated control design methodologies is not readily available. Therefore, in this paper, a detailed model of a grid-connected singlephase two-stage PV system with component level models and associated control design procedures, is presented. The model of the grid-connected PV system is developed in the PSCAD/EMTDC simulation program.

This paper is organised in the following manner. In Section II, component level models of the grid-connected singlephase two-stage PV system and the maximum power point tracking (MPPT) algorithm are described. The design of the synchronous reference frame phase-lock-loop (s-PLL) for grid synchronisation, the cascaded control of the voltage source 
converter (VSC), the controller of the dc-dc converter are described in Section III. Finally, in Section IV, effectiveness of the developed model of the grid-connected single-phase twostage PV system is evaluated with simulation studies.

\section{Modelling}

The modelled PV system shown in Fig. 1 consists of component models of a PV array, a voltage source converter (VSC), an LCL filter, a dc-dc boost converter and a model of a power distribution grid. Component level models of the PV system are described in this section including the MPPT algorithm.

\section{A. PV Array and MPPT Algorithm}

The single-diode PV array model is adopted from [10]. The V-I characteristic curves of the PV array are shown in Fig. 2 for different solar irradiance levels while the ambient temperature is at $30{ }^{\circ} \mathrm{C}$. The voltage at the maximum power point (MPP), $V_{\text {mpp }}$, at each irradiance level is marked in Fig. 2 .

The amount of maximum power that can be extracted from the PV array at a given time is a function of the solar irradiance and the ambient temperature. Since the solar irradiance and the ambient temperature is continuously changing, an MPPT algorithm is necessary to track the MPP. Among the available MPPT algorithms, the perturb and observe (P\&O) method and the incremental conductance ( $\mathrm{InC}$ ) method are two well known MPPT algorithms. The P\&O method has been identified as a simple but a slow tracking MPPT algorithm. Further, under rapid variations of solar irradiance the $\mathrm{P} \& \mathrm{O}$ method can fail [11]. The InC method performs well under rapid variations of solar irradiance [12]. Hence in the developed simulation model of the PV system, the InC method is used.

The flowchart of the InC algorithm is shown in Fig. 3. In the flowchart $t$ and $(t-1)$ indicate the current sample time and the previous sample time, $\Delta V$ and $\Delta I$ are differences in two consecutive samples of the output voltage and the current at the PV array output respectively, $V_{\text {ref }}(t)$ is the voltage of the MPP that is found by the InC algorithm at the end of a iteration and $\delta V$ is the amount of voltage that is added/subtracted to/from $V_{\text {ref }}(t-1)$ in the process of finding MPP after each iteration.

\section{B. Voltage Source Converter}

The VSC in Fig. 1 is a full-bridge converter that is made of insulated gate bi-polar transistor switches. The VSC is able to operate in all four quadrants. The rated apparent power capacity of the VSC, $S_{\mathrm{r}}$, is $5.4 \mathrm{kVA}$. The spare capacity of the VSC when injecting a certain amount of active power is used for injecting or absorbing reactive power. The switching frequency of the VSC, $f_{\mathrm{sw}}$, is $25 \mathrm{kHz}$ and a unipolar sinusoidal pulse width modulation technique is used [13].

\section{LCL Filter}

The LCL filter components of the PV system shown in Fig. 1 were calculated as $L_{\mathrm{fc}}=300 \mu \mathrm{H}, L_{\mathrm{fg}}=150 \mu \mathrm{H}$ and $C_{\mathrm{f}}=2.2 \mu \mathrm{F}$, by following the LCL filter design procedure described in [14]. Resistances of inductances $L_{\mathrm{fc}}$ and $L_{\mathrm{fg}}$ are assumed as $R_{\mathrm{fc}}, R_{\mathrm{fg}}=0.001 \Omega$. The total inductance of the designed LCL filter is less than $0.1 \mathrm{pu}$ (base- $S_{\mathrm{b}}=5.4 \mathrm{kVA}$,
$V_{\mathrm{b}}=230 \mathrm{~V}$ ) and the resonant frequency, $f_{\text {res }}$, is $10.7 \mathrm{kHz}$; less than $0.5 f_{\mathrm{sw}}$. A damping resistor $R_{\mathrm{d}}=2 \Omega$, calculated as one third of the impedance of $C_{\mathrm{f}}$ at $f_{\text {res }}$, is added in series with $C_{\mathrm{f}}$ to improve the stability of the current controller [15] that is discussed in Section III-B.

\section{Selection of Dc-link Capacitor}

The dc-link voltage, $V_{\mathrm{dc}}$, consists of an average dc component, $V_{\mathrm{dc} \_a v g}$, as well as a $100 \mathrm{~Hz}$ voltage ripple. An expression for the peak-to-peak $100 \mathrm{~Hz}$ voltage ripple, $\Delta V_{\mathrm{dc}}$, of the dc-link can be derived as (1) [16]. In (1) $P_{\mathrm{g}}$ is the active power injected to the grid $C_{\mathrm{dc}}$ is the dc-link capacitor and $\omega$ is the fundamental angular frequency of the grid voltage, $v_{\mathrm{g}}$. $V_{\text {dc_avg }}$ is $400 \mathrm{~V}$ of the modelled PV system.

$$
\Delta V_{\mathrm{dc}}=\frac{P_{\mathrm{g}}}{C_{\mathrm{dc}} V_{\mathrm{dc} \_a v g} \omega}
$$

In the modelled PV system, $C_{\mathrm{dc}}$ is calculated as $2200 \mu \mathrm{F}$ to limit $\Delta V_{\mathrm{dc}}$ to approximately $5 \%$ of $V_{\mathrm{dc} \_a v g}$ when the VSC is injecting $5.4 \mathrm{~kW}$ of active power to the power distribution grid.

\section{E. Dc-dc Boost Converter}

The rated capacity of the dc-dc boost converter shown in Fig. 1 is $5 \mathrm{~kW}$ and the switching frequency, $f_{\mathrm{dc}}$, is $10 \mathrm{kHz}$. The inductor, $L_{\mathrm{dc}}$, can be calculated as given in (2) to limit the current ripple, $\Delta I$, of the current that is flowing through the inductor [13]. In (2), $V_{\mathrm{pv}}$ is the voltage across the PV array.

$$
L_{\mathrm{dc}}=\frac{V_{\mathrm{pv}}\left(V_{\mathrm{dc} \_\mathrm{avg}}-V_{\mathrm{pv}}\right)}{\Delta I f_{\mathrm{dc}} V_{\mathrm{dc} \_a v g}}
$$

If the PV array is operated close to the MPP, $V_{\mathrm{pv}}$ is close to $300 \mathrm{~V}$ as per Fig. 2. Hence the inductor, $L_{\mathrm{dc}}=9 \mathrm{mH}$, can be calculated to limit $\Delta I$ to $5 \%$ when the dc-dc boost converter is operating at the rated capacity.

The dc-dc boost converter decouples the PV array from ac-side dynamics [16]. Therefore, in modelling the gridconnected PV system, the capacitor $C_{\mathrm{pv}}$ at the PV array output is chosen to be 2.5 times the dc-link capacitor, $C_{\mathrm{dc}}$. With the selected value for $C_{\mathrm{pv}}$, the $100 \mathrm{~Hz}$ voltage ripple that is appeared across the PV array is reduced to $10 \%$ of the $100 \mathrm{~Hz}$ voltage ripple of the dc-link when the VSC is operated at the rated capacity. The high time constant of $C_{\mathrm{pv}}$ effectively decouples the ac-side and the dc-side of the grid-connected $\mathrm{PV}$ system. The capacitor, $C_{\mathrm{pv}}$ also minimises the switching ripple current that is drawn from the PV array.

\section{F. Power Distribution Grid}

The power distribution grid is modelled with an equivalent Thèvenin voltage source, $v_{\mathrm{s}}$ and a series impedance $\left(R_{\mathrm{g}}+j X_{\mathrm{g}}\right)$ as shown in Fig. 1. The reference impedance for low voltage public supply systems that is given in [17] for electrical apparatus testing purposes is used to model the power distribution grid. Hence the grid impedance, $\left(R_{\mathrm{g}}+j X_{\mathrm{g}}\right)$ is $(0.4+j 0.25) \Omega$. 


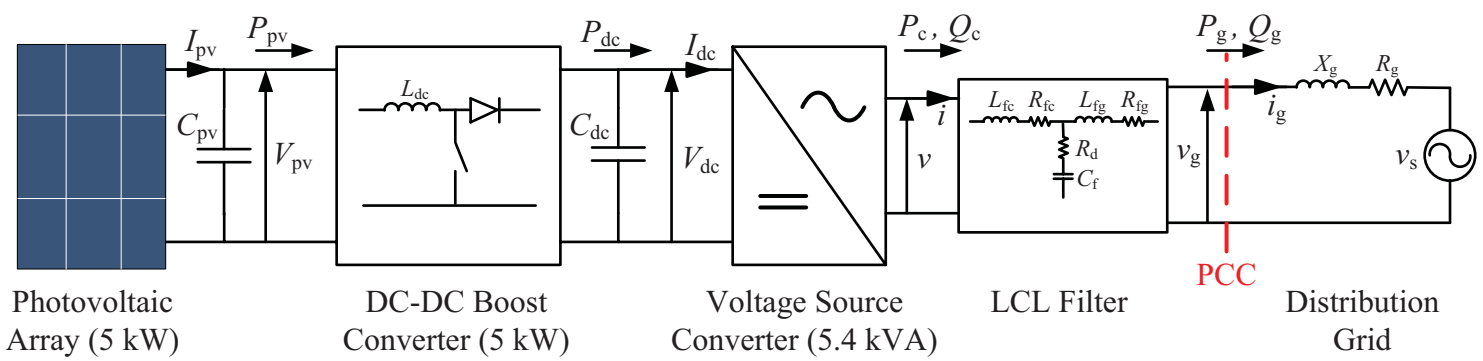

Fig. 1. Grid-connected PV system with a two-stage converter.

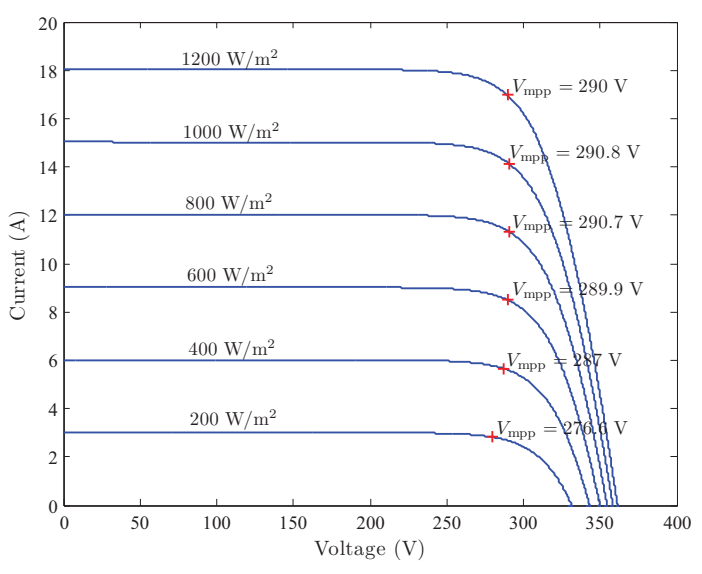

Fig. 2. V-I characteristic curve of the PV array.

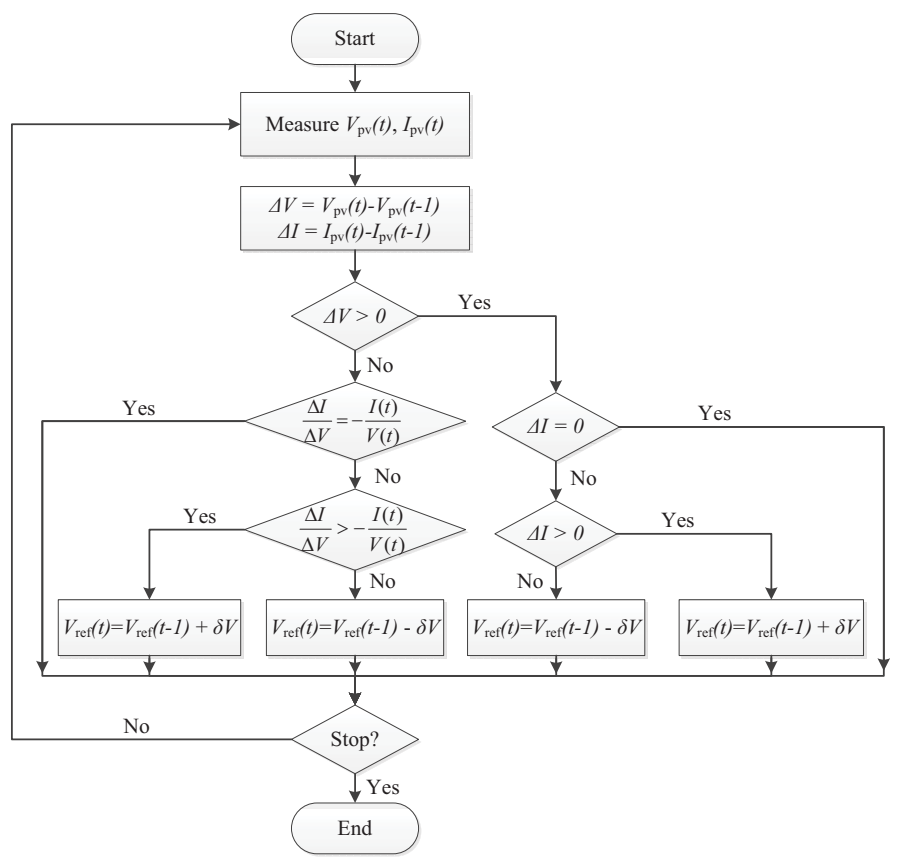

Fig. 3. Flow chart of the $\mathrm{InC}$ algorithm [12].

\section{Control Design}

The control designing for the PV system includes a grid synchronisation mechanism, a current controller, a dc-link voltage controller, a power factor controller and a dc-dc boost converter controller. The design procedures of those control systems are described in this section.

\section{A. Grid Synchronisation}

The synchronous reference frame phase-locked-loop (sPLL) of a single-phase system requires the generation of an imaginary orthogonal signal from the measured grid voltage, $v_{\mathrm{g}}$ of the single-phase VSC. A structure based on a second order generalised integrator (SOGI) is proposed in [18] to create an imaginary orthogonal signal from the measured grid voltage signal. A similar response of the structure proposed in [18] can be obtained by combining a second order band-pass filter and a simple integrator that is scaled by the nominal grid frequency, $\omega=100 \pi \mathrm{rad} / \mathrm{s}$. The proposed structure not only creates an imaginary orthogonal signal without any delays but also filters out the harmonics in $v_{\mathrm{g}}$. The transfer function of the standard second order band-pass filter is given in (3) [19]. In (3), $\omega_{0}$ is the centre frequency of the band-pass filter, $Q$ is the quality factor and $H$ is the desired de gain for a signal of the frequency $\omega_{0}$. The bandwidth, $B W$, of the second order band-pass filter is given in (4).

$$
\begin{gathered}
G_{\mathrm{bp}}(s)=\frac{H\left(\omega_{0} / Q\right) s}{s^{2}+\left(\omega_{0} / Q\right) s+\omega_{0}^{2}} \\
B W=\frac{\omega_{0}}{Q}
\end{gathered}
$$

The structure of the single-phase s-PLL is as depicted in Fig. 4. As indicated in Fig. $4, V_{\alpha}$ and $V_{\beta}$ are the filtered grid voltage signal and the imaginary orthogonal signal respectively, $P(s)$ is a compensator and, $\omega_{\mathrm{e}}$ and $\vartheta$ are the estimated angular frequency and the phase angle of $v_{\mathrm{g}}$. If $\vartheta$ is very close to the actual phase angle of $v_{\mathrm{g}}, V_{d} \approx V_{m}$ (the peak value of $\left.v_{\mathrm{g}}\right)$ and $V_{q} \approx 0$.

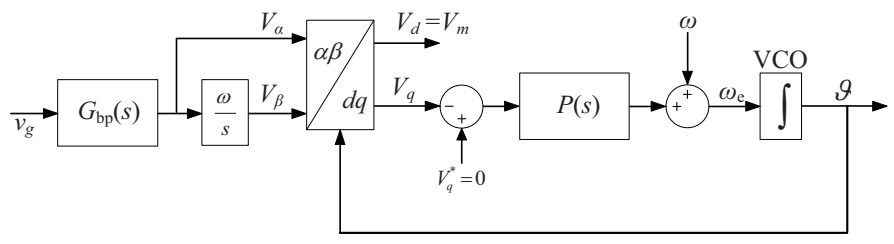

Fig. 4. Structure of the single-phase s-PLL.

The main function of the band pass filter is to filter out the harmonics in $v_{\mathrm{g}}$. Therefore a narrow bandwidth is desired in the band-pass filter so that the low-order harmonics are highly attenuated. Hence a higher $Q$ is desired according to (4). But also a very low bandwidth slows down the dynamic response of the filter. Therefore a very high value for $Q$ cannot be chosen. In this work, $Q$ is chosen to be 1.25 , so that 
the $\mathrm{BW}=40 \mathrm{~Hz}$ for a signal of $\omega_{0}=100 \pi \mathrm{rad} / \mathrm{s}$. Since neither attenuation nor gain is desired for the fundamental frequency grid voltage signal $v_{\mathrm{g}}, H=1$. The settling time of the designed band-pass filter is $30 \mathrm{~ms}$. The control loop of the single-phase s-PLL consists only a pole at zero that is of the voltage-controlled-oscillator (VCO). A PI regulator is chosen as the compensator $P(s)$. The gains of the PI compensator are tuned as $k_{\mathrm{pp}}=115$ and $k_{\mathrm{ip}}=6600$. The settling time of the closed-loop system is approximately $70 \mathrm{~ms}$.

\section{B. Current Controller}

The stationary frame closed-loop current controller is designed using the proportional resonant (PR) regulator introduced in [20]. The transfer function of the non-ideal PR controller with fundamental frequency compensator and loworder odd harmonic compensators (HC), is given in (5) [21]. In (5), $k_{\mathrm{pc}}$ is the proportional gain, $k_{\mathrm{ich}}$ is the integral gain and $\omega_{c}$ is the $3 \mathrm{~dB}$ cut-off frequency.

$$
C(s)=k_{\mathrm{pc}}+\sum_{h=1,3,5,7} \frac{2 k_{\mathrm{ich}} \omega_{c} s}{s^{2}+2 \omega_{c} s+\left(h \omega_{o}\right)^{2}}
$$

The control plant model of the stationary frame current controller can be derived as (6) by simplifying the LCL filter to an $\mathrm{L}$ filter. The simplification is justifiable since the impedance of $C_{\mathrm{f}}$ at low frequencies is high. In (6) $L_{\mathrm{T}}=L_{\mathrm{fc}}+L_{\mathrm{fg}}+L_{\mathrm{g}}$ and $R_{\mathrm{T}}=R_{\mathrm{fc}}+R_{\mathrm{fg}}$.

$$
C(s)=\frac{I_{\mathrm{g}}(s)}{V(s)}=\frac{1}{L_{\mathrm{T}} s+R_{\mathrm{T}}}
$$

The closed-loop current controller is shown in Fig. 5 assuming a unity feedback loop. The dynamics of the VSC are neglected since the developed model is a continuous timedomain model. In Fig. 5, $e_{\mathrm{c}}$ is the difference between the current reference $i_{\text {g_ref }}$ that is given by (7) (where $V_{\mathrm{m}}$ and $\vartheta$ are obtained from the single-phase s-PLL and, $P_{\text {ref }}$ and $Q_{\text {ref }}$ are active and reactive power references respectively) and the injected current to the grid $i_{\mathrm{g}}, u_{\mathrm{c}}$ is the output of the PR regulator $C(s)$ and $m_{\mathrm{c}}$ is the modulation index of of the VSC.

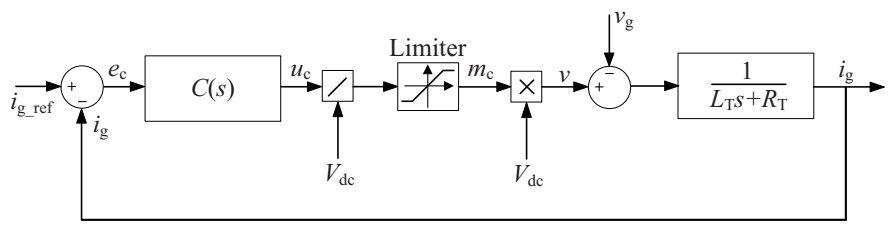

Fig. 5. Closed-loop current controller of the single-phase VSC system [22].

$$
i_{\mathrm{g} \_ \text {ref }}=\frac{2 \sqrt{P_{\text {ref }}^{2}+Q_{\text {ref }}^{2}}}{V_{\mathrm{m}}} \cos \left(\vartheta+\arctan \left(Q_{\text {ref }} / P_{\text {ref }}\right)\right)
$$

In the designed $\mathrm{PR}$ regulator $C(s), k_{\mathrm{pc}}=4$ is calculated to obtain a $500 \mathrm{~Hz}$ bandwidth for the closed-loop current controller, $k_{\mathrm{ic} 1}=100$ to have zero steady-state error and the integral gains of the $\mathrm{HC}$ are $k_{\text {ich }}=80(h=3,5,7)$. The $3 \mathrm{~dB}$ cut-off frequency, $\omega_{c}$, is selected to be $5 \mathrm{rad} / \mathrm{s}$ [21].

\section{Dc-link Voltage Controller}

The dc-link voltage of the VSC is regulated at $400 \mathrm{~V}$. The transfer function of the control plant model of the dc-link voltage can be derived as (8) assuming power balance at ac and dc sides of the VSC.

$$
G_{V_{\mathrm{dc}}}(s)=\frac{V_{\mathrm{dc}}^{2}(s)}{P_{\mathrm{g}}(s)}=-\frac{2}{C s}
$$

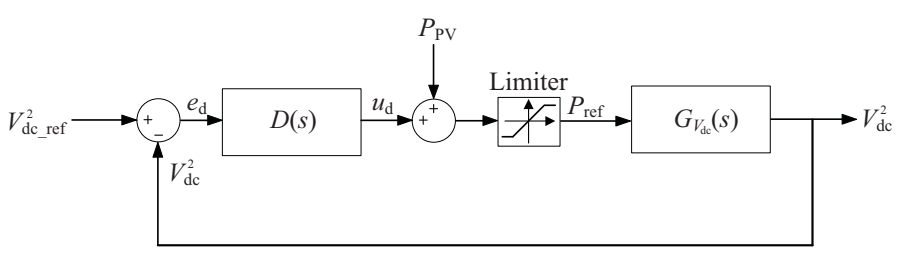

Fig. 6. The dc-link voltage control diagram.

The control block diagram of the dc-link voltage controller is given in Fig 6. In Fig. 6, $D(s)$ is a compensator, $e_{\mathrm{d}}$ and $u_{\mathrm{d}}$ are the dc-link voltage error and the compensator output respectively. In order to improve the dynamic response of the dc-link voltage controller in the presence of rapid changes of power at the PV array, the power feed-forward signal $P_{\mathrm{pv}}$ has been added to the controller [22]. $P_{\mathrm{pv}}$ is calculated from the measured voltage, $V_{\mathrm{pv}}$ and the current, $I_{\mathrm{pv}}$ that are shown in Fig 1. The compensator output $u_{\mathrm{d}}$ is mostly the amount of power that is needed to compensate for the losses in the grid-connected PV system. In Fig $6, P_{\text {ref }}$ is the amount of active power that should be injected by the VSC to the power distribution grid to control the average voltage of the dclink at the the reference value, $V_{\text {dc_ref. Hence }} P_{\text {ref }}$ is the active power reference of the current controller and the current control loop becomes an inner control loop of the dc-link voltage controller. Therefore, for proper tracking of $V_{\mathrm{dc} \_ \text {ref }}$, the bandwidth of the dc-link voltage controller is chosen as one tenth of the bandwidth of the closed-loop current controller. Since the bandwidth of the dc-link voltage controller is much smaller than that of the current controller, the dynamics of the current controller can be disregarded while designing the dc-link voltage controller.

A gain, $k_{\mathrm{pd}}$, is used as the compensator $D(s)$. Assuming a unity feedback loop, the transfer function of the closed-loop dc-link voltage controller is given in (9). $k_{\mathrm{pd}}$ is calculated as -0.345 to obtain approximately a $50 \mathrm{~Hz}$ bandwidth for the dc-link voltage controller.

$$
G_{\mathrm{dc}_{-} \mathrm{cl}}(s)=\frac{-2 k_{\mathrm{pd}}}{C_{\mathrm{dc}} s-2 k_{\mathrm{pd}}}
$$

The $100 \mathrm{~Hz}$ voltage ripple of the dc-link voltage feedback signal $V_{\mathrm{dc}}$ is filtered out by using a notch filter.

\section{Dc-dc Boost Converter Controller}

The controller of the dc-dc boost converter is shown in Fig. 7. $V_{\text {ref }}$ is the voltage of the MPP calculated by the $\mathrm{InC}$ algorithm after each iteration and is used as the reference for the PV array side voltage of the dc-dc boost converter. $V_{\text {ref }}$ is compared with the voltage across the PV array, $V_{\mathrm{pv}}$. The error signal, $e_{\mathrm{b}}$, is processed by the compensator $B(s)$ to determine 


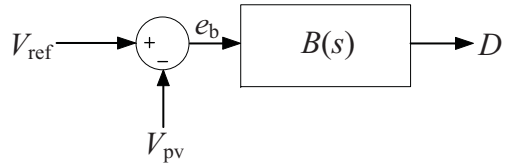

Fig. 7. Controller of the dc-dc boost converter.

the duty cycle, $D$ of the dc-dc boost converter. The controller of the dc-dc boost converter adjusts $D$ in such a way that $V_{\mathrm{pv}}$ is regulated at $V_{\text {ref }}$.

A PI regulator is chosen as $B(s)$. The PI regulator is tuned as the proportional gain $k_{\mathrm{pb}}=0.002$ and the integral gain $k_{\mathrm{ib}}=100$ using a trial and error method.

\section{E. Power Factor Controller}

The VSC is allowed to operate in the range from 0.8 leading to 0.95 lagging power factor (considering the VSC as a load connected to the grid) according to Australian Std. AS4777.2 [23]. Since the operating range of the grid-connected PV system can be enhanced by operating the VSC at a lagging power factor the active and reactive power characteristic curve shown in Fig. 8 is implemented to operate the VSC at the maximum allowed lagging power factor. In Fig. 8, $P_{\mathrm{g}}$ is the active power injected to the grid, $Q_{\text {ref }}$ is the reference of the reactive power injected to the grid, $Q_{\mathrm{g}}, P_{\mathrm{o}}=0.2 S_{\mathrm{r}} \mathrm{kW}$ (as per [23]), $P_{\max }=5 \mathrm{~kW}$ and $-Q_{\max }=-1.65 \mathrm{kVAr}$.

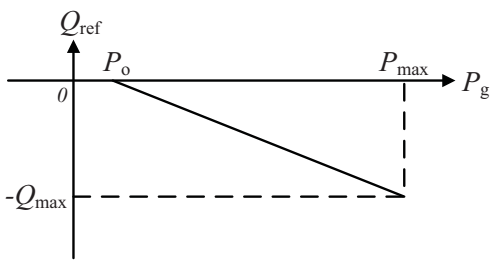

Fig. 8. Active and reactive power characteristics of the VSC for power factor control.

\section{Simulation Results}

The simulation model of the grid-connected single-phase two-stage PV system was developed in the PSCAD/EMTDC simulation program. Simulation studies were performed to evaluate the effectiveness of models and controllers of the PV system. The surface temperature of the PV array was considered constant at $30{ }^{\circ} \mathrm{C}$ in all simulation scenarios.

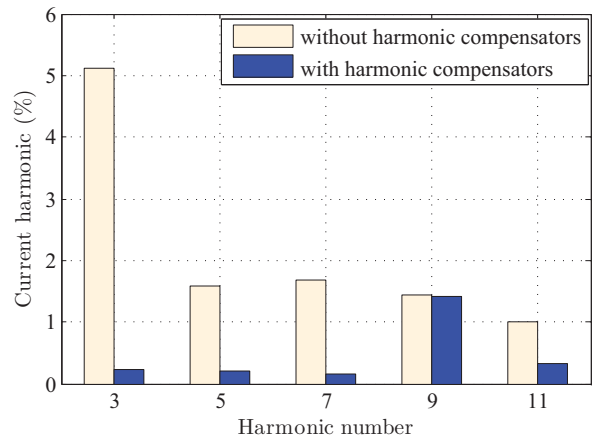

Fig. 9. Harmonic spectrum of the measured grid current.

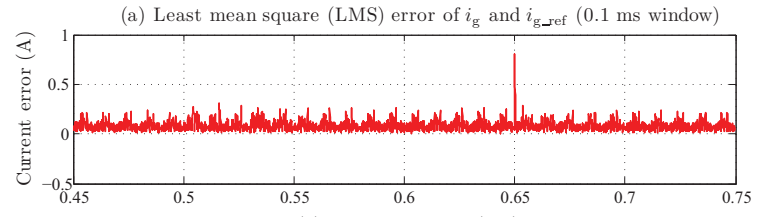

(b) DC link voltage $\left(V_{\mathrm{dc}}\right)$
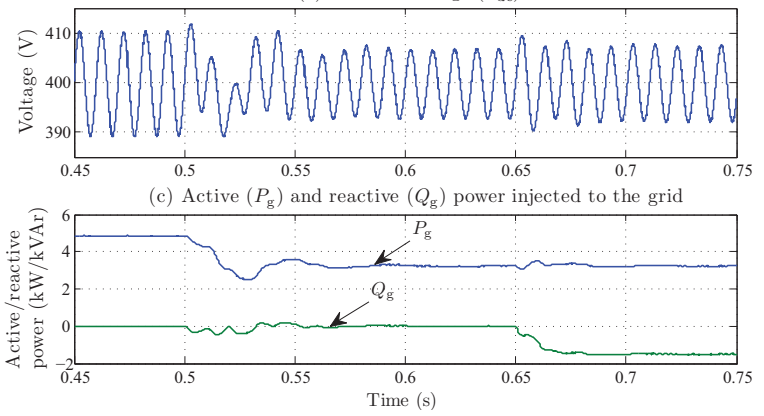

Fig. 10. System response for step changes of solar irradiance and reactive power reference.
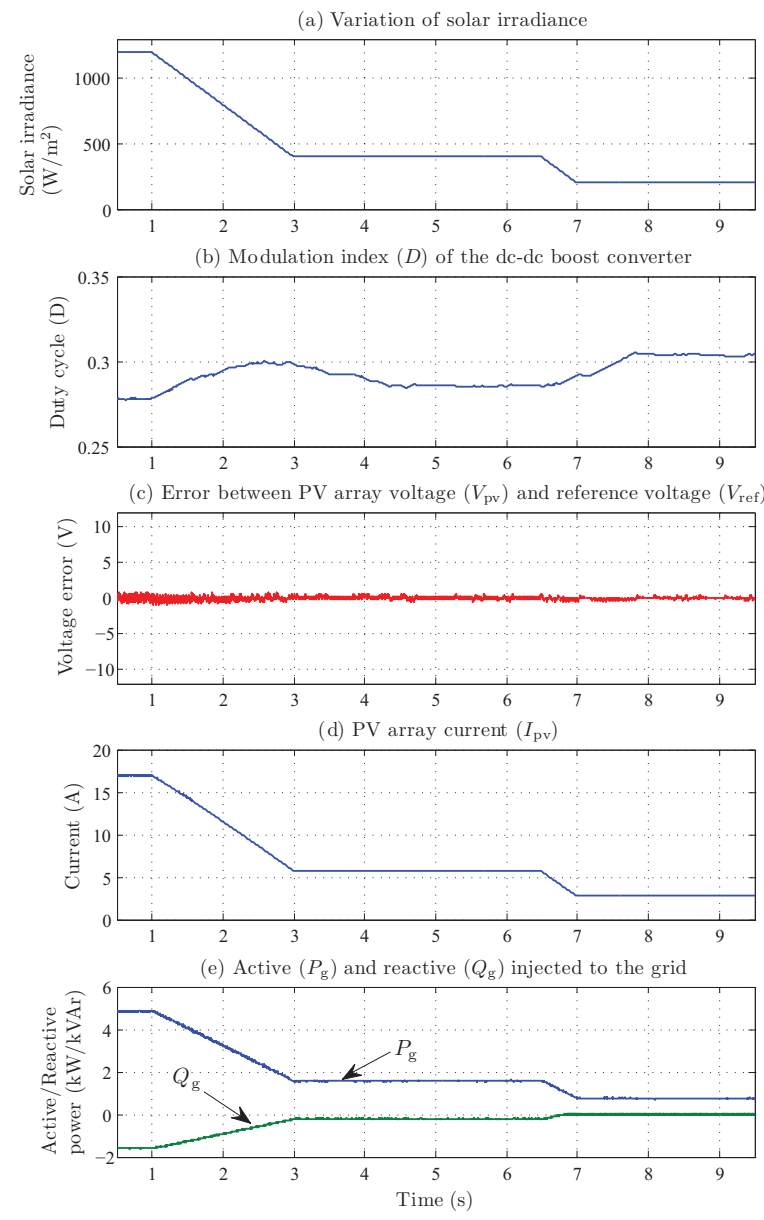

Fig. 11. System response for a ramping solar irradiance variation.

The VSC was operated at the rated capacity with and without the low-order HC. The total harmonic distortion (THD) of the simulated grid voltage was zero. The magnitudes of low-order current harmonics injected to the power distribution grid as a percentage of the fundamental current is shown in Fig. 9. The calculated THD with and without $\mathrm{HC}$ was $5.9 \%$ 
and $1.5 \%$ respectively.

Fig. 10 illustrates the response of the closed-loop current controller and the dc-link voltage controller for step changes of solar irradiance (from 1200 to $800 \mathrm{~W} / \mathrm{m}^{2}$ at $t=0.5 \mathrm{~s}$ ) and reactive power (from 0 to $-1.5 \mathrm{kVAr}$ at $t=0.65 \mathrm{~s}$ ). In the designed PV system, a new current reference is generated upon a operating state change. As the closed-loop current controller closely tracks the generated current reference, the steadystate error is almost zero as shown in Fig. 10(a). Fig. 10(c) illustrates the capability of the designed current controller to independently control the injected active and reactive power.

The performance of the MPPT algorithm, controller of the dc-dc boost converter and the power factor controller of the VSC are shown in Fig. 11 with the variation of solar irradiance illustrated in Fig. 11(a). The controller of the dc-dc boost converter has closely regulated the $\mathrm{PV}$ array voltage, $V_{\mathrm{pv}}$ at $V_{\text {ref }}$ by adjusting the duty cycle of the dc-dc boost converter. The VSC was operated at 0.95 lagging power factor as that can be seen in Fig. 11(e).

Fig. 12 illustrates the MPP tracking path of the considered variations in the solar irradiance shown in Fig. 11(a).

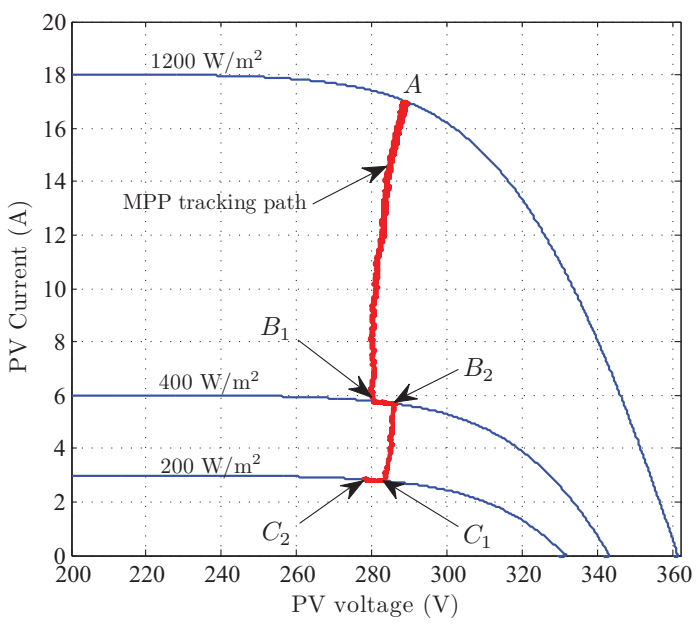

Fig. 12. MPP tracking path.

During the ramping time of the solar irradiance, the MPP has deviated away $\left(B_{1}\right.$ and $\left.C_{1}\right)$ from the actual value $\left(B_{2}\right.$ and $C_{2}$ ). But once the solar irradiance is stabilised, the actual MPP has been found accurately by the MPPT algorithm.

\section{CONCLUSIONS}

A component level model of a grid-connected single-phase two-stage photovoltaic (PV) system with associated controllers is presented in the paper. The effectiveness of the developed model, with theoretically established component values and designed controllers, is evaluated with simulation studies. The robustness and the accuracy of the designed grid synchronisation mechanism, the stationary frame current controller and the dc-link voltage controller are verified with time-domain simulation studies that are illustrated with rapid changes in solar irradiance and reactive power reference. The harmonic current that is injected by the voltage source converter (VSC) of the PV system is minimised by the harmonic compensators that are implemented in the current controller. The controller of the PV system is capable of independently controlling the active power and the reactive power injected to the grid. The active power injection to the grid is enhanced by adding a maximum power point tracking (MPPT) algorithm. The maximum power point (MPP) tracking accuracy of the MPPT algorithm and the performance of the designed controller for the dc-dc boost converter have demonstrated under rapid variations of the solar irradiance. The reactive power injected by the VSC is controlled by operating the VSC at the maximum lagging power factor that is specified in the Australian Std. AS4777.2.

\section{ACKNOWLEDGEMENT}

The authors gratefully acknowledge Dr. Athula Rajapakse, University of Manitoba, Canada, for providing the PSCAD/EMTDC model of the photovoltaic array.

\section{REFERENCES}

[1] E. Caamaño et al. (2007, Jul.) State-of-the-art on dispersed PV power generation: impact of PV distributed generation and electricity networks. Intelligent Energy. Europe. [Online]. Available: http://www.pvupscale.org/IMG/pdf/D41_final.pdf

[2] L. Freris and D. Infield, Renewable Energy in Power Systems. Wiley, 2008.

[3] B. Kroposki, C. Pink, R. DeBlasio, H. Thomas, M. Simões, and P. Sen, "Benefits of power electronic interfaces for distributed energy systems," IEEE Trans. Energy Convers., vol. 25, no. 3, pp. 901-908, Sep. 2010.

[4] E. Caamanõ-Martín et al., "Interaction between photovoltaic distributed generation and electricity networks," Progress in Photovoltaics: Research and Applications, vol. 16, no. 7, pp. 629-643, Aug. 2008. [Online]. Available: http://www.interscience.wiley.com

[5] J. Enslin and P. Heskes, "Harmonic interaction between a large number of distributed power inverters and the distribution network," IEEE Trans. Power Electron., vol. 19, no. 6, pp. 1586-1593, Nov. 2004.

[6] M. Liserre, R. Teodorescu, and F. Blaabjerg, "Stability of photovoltaic and wind turbine grid-connected inverters for a large set of grid impedance values," IEEE Trans. Power Electron., vol. 21, no. 1, pp. $263-272$, Jan. 2006.

[7] J. Puukko, T. Messo, and T. Suntio, "Effect of photovoltaic generator on a typical VSI-based three-phase grid-connected photovoltaic inverter dynamics," in Proc. IET Conf. on Renewable Power Generation RPG'11, Sep. 2011, pp. 1-6.

[8] M. Molina and P. Mercado, "Modeling and control of grid-connected photovoltaic energy conversion system used as a dispersed generator," in Proc. IEEE/PES Transmission and Distribution Conf. and Exposition, Aug. 2008, pp. 1-8

[9] M. Ciobotaru, T. Kerekes, R. Teodorescu, and A. Bouscayrol, "PV inverter simulation using MATLAB/Simulink graphical environment and PLECS blockset," in Proc. 32nd Annu. IEEE Conference on Industrial Electronics, IECON'06, Nov. 2006, pp. 5313-5318.

[10] A. Rajapakse and D. Muthumuni, "Simulation tools for photovoltaic system grid integration studies," in Proc. IEEE Electrical Power Energy Conf. EPEC'09, Oct. 2009, pp. 1-5.

[11] T. Esram and P. Chapman, "Comparison of photovoltaic array maximum power point tracking techniques," IEEE Trans. Energy Convers., vol. 22 , no. 2, pp. 439-449, Jun. 2007.

[12] K. Hussein, I. Muta, T. Hoshino, and M. Osakada, "Maximum photovoltaic power tracking: an algorithm for rapidly changing atmospheric conditions," vol. 142, no. 1, Jan. 1995, pp. 59-64.

[13] M. H. Rashid, Power Electronics, 3rd ed. Upper Saddle River, NJ: Prentice Hall, 2004

[14] M. Liserre, F. Blaabjerg, and S. Hansen, "Design and control of an LCLfilter-based three-phase active rectifier," IEEE Trans. Ind. Appl., vol. 41, no. 5, pp. 1281-1291, Sep.-Oct. 2005.

[15] M. Liserre, A. Dell'Aquila, and F. Blaabjerg, "Stability improvements of an LCL-filter based three-phase active rectifier," in Proc. 33rd Annu. IEEE Power Electronics Specialists Conf. PESC'02, vol. 3, 2002, pp. $1195-1201$

[16] F. Gao, D. Li, P. C. Loh, Y. Tang, and P. Wang, "Indirect dc-link voltage control of two-stage single-phase PV inverter," in Proc. IEEE Energy Conversion Congress and Exposition ECCE'09, Sep. 2009, pp. 11661172.

[17] "Electromagnetic Compatibility (EMC) - Consideration of reference impedance and public supply network impedances for use in determining disturbances characteristics of electrical equipment having a rated current $\leq 75$ A per phase," IEC, Tech. Rep. 77A/753/CD, Jun. 2011. 
[18] M. Ciobotaru, R. Teodorescu, and F. Blaabjerg, "A new single-phase PLL structure based on second order generalized integrator," in Proc. 37th Annu. IEEE Power Electronics Specialists Conf. PESC'06, Jun. 2006, pp. 1-6.

[19] M. E. Van Valkenburg, Analog Filter Design. CBS College, 1982.

[20] D. Zmood and D. Holmes, "Stationary frame current regulation of PWM inverters with zero steady-state error," IEEE Trans. Power Electron., vol. 18 , no. 3, pp. 814-822, May 2003.

[21] R. Teodorescu, F. Blaabjerg, M. Liserre, and P. Loh, "Proportionalresonant controllers and filters for grid-connected voltage-source converters," Proc. IEE Electric Power Applications, vol. 153, no. 5, pp. 750-762, Sep. 2006.

[22] A. Yazdani and R. Iravani, Voltage-Sourced Converters in Power Systems. Wiley/IEEE, 2010.

[23] Grid Connection of Energy Systems via Inverters - Part 2: Inverter Requirements, Australian Std. AS4777.2, 2005. 